\title{
Effect of repeated cycles of chemical disinfection in microhardness of acrylic resins of complete denture base
}

\author{
Efeito de repetidos ciclos de desinfecção química na microdureza de resinas acrílicas de base de prótese total
}

Elisa das Graças MARTINS'

Rafael Tobias MORETTI NETO'

\section{ABSTRACT}

\section{Objective}

To evaluate the microhardness of specimens of acrylic resins VipiCril ${ }^{\circledR}$ (thermally polymerized resin) and Bosworth New Truliner ${ }^{\circledR}$ (selfpolymerized resin), before and after immersion in solutions of $0.12 \%$ chlorhexidine digluconate, $1 \%$ sodium hypochlorite, Corega Tabs ${ }^{\circledR}$ and water (control), testing the null hypothesis that the mouthwashes and chemicals used to disinfect complete dentures do not interfere with the superficial microhardness, and can therefore be used as adjuncts to oral hygiene of edentulous patients.

\section{Methods}

Sixty specimens of resin VipiCril ${ }^{\circledR}$ (thermally polymerized resin) and 60 specimens of resin Bosworth New Truliner ${ }^{\circledR}$ (self-polymerized resin) measuring $16 \mathrm{~mm}$ of diameter and $6 \mathrm{~mm}$ of height were prepared, which were randomly divided into four groups of 15 specimens each, undergoing Knoop hardness tests (KHN) both before and after cycles of immersion in solutions of $0.12 \%$ chlorhexidine digluconate, $1 \%$ sodium hypochlorite, Corega Tabs ${ }^{\circledR}$ and water (control).

\section{Results}

The specimens of resins VipiCril and Bosworth immersed in solutions of $0.12 \%$ chlorhexidine, Corega Tabs ${ }^{\circledR}$ and water showed decreased microhardness.

\section{Conclusion}

The $1 \%$ sodium hypochlorite solution caused least damage to the denture structure, not leading to decrease of the superficial microhardness.

Indexing terms: Acrylic resins. Dental prosthesis. Disinfection.

\section{RESUMO}

\section{Objetivo}

Avaliar a microdureza de corpos de prova das resinas acrílicas VipiCril ${ }^{\circledR}$ (resina termopolimerizável) e Bosworth New Truliner ${ }^{\circledR}$ (resina autopolimerizável), antes e após, a imersão em soluções de digluconato de clorexidine a 0,12\%, hipoclorito de sódio a $1 \%$, Corega Tabs ${ }^{\circledR}$ e água (controle), testando a hipótese nula de que os enxaguatórios bucais e substâncias químicas utilizadas na desinfecção de próteses totais não interferem na microdureza superficial, podendo assim, serem utilizados como coadjuvantes na higiene bucal de pacientes desdentados.

\section{Métodos}

Foram confeccionados 60 corpos de prova da resina VipiCril ${ }^{\circledR}$ (termopolimerizável) e 60 corpos de prova da resina Bosworth New Truliner ${ }^{\circledR}$ (autopolimerizável) com $16 \mathrm{~mm}$ de diâmetro por $6 \mathrm{~mm}$ de altura, estes foram divididos randomicamente em quatro grupos de 15 amostras cada, sendo submetidos a testes de microdureza Knoop (KHN), antes e após, ciclos de imersões em soluções de digluconato de clorexidine a

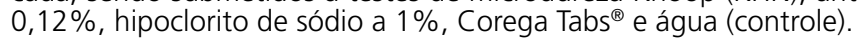

\section{Resultados}

Os corpos de prova de resina VipiCril e Bosworth imersos nas soluções de clorexidine a 0,12\%, Corega Tabs ${ }^{\circledR}$ e água apresentaram diminuição de microdureza.

\section{Conclusão}

A solução de hipoclorito de sódio a 1\% causou menor dano à estrutura da prótese não causando diminuição da microdureza superficial.

Termos de indexação: Resinas acrílicas. Prótese dentária. Desinfecção.

\footnotetext{
${ }^{1}$ Universidade Federal de Alfenas, Departamento de Clínica e Cirurgia. Rua Gabriel Monteiro da Silva, 714, Centro, 37130-000, Alfenas, MG, Brasil. Correspondência para / Correspondence to: EG MARTINS. E-mail: <elyssa.martins@hotmail.com>.
} 


\section{INTRODUCTION}

The proper maintenance of removable dental prostheses is required for users of complete denture base in order to have a pleasant aesthetics, dentures free from odors and good oral health ${ }^{1}$.

The increase in health expectancy of people was followed by an increased interest in dental treatment on the part of elderly patients who were concerned not only with aesthetics but also with oral health ${ }^{2-3}$. However, many elderly subjects are affected by diseases that limit their manual ability ${ }^{3-4}$, thus requiring complementation of the mechanical cleaning with chemical substances in order to avoid the accumulation of dental microbial plaque on the oral mucosa membrane and on the surfaces of dentures, what may lead to the development of several diseases, such as candidiasis ${ }^{5-6}$.

Among hygiene protocols we can say that mechanical cleaning is an effective method that keeps the mucosa membrane and denture clean ${ }^{6-8}$, as well as chemical hygienization, which uses solutions such as sodium hypochlorite, alkaline glutaraldehyde, aqueous formaldehyde, chlorhexidine digluconate solution, enzymatic solutions and sodium perborate solutions. An effective alternative method that has been currently used is microwave irradiation to fight several diseases and eliminate colonization by Candida albicans (,8-12. $^{\text {8. }}$

However, the chemical disinfection methods available for partial and complete denture bases may cause alteration of physical and mechanical properties of the materials used in the composition of such denture bases. Clinical characteristics such as rugosity, hardness, dimensional stability of color and bending properties can be changed after immersion in those solutions ${ }^{1,11,13}$.

Therefore, the purpose of this study was to assess the microhardness of resins (self- and thermally polymerized) for complete denture base after the disinfection cycles using chemicals such as $0.12 \%$ chlorhexidine digluconate, $1 \%$ sodium hypochlorite (200mL in a $500-\mathrm{mL}$ beaker), and Corega Tabs $^{\circledR}$ (diluted in $200 \mathrm{~mL}$ of distilled water in a $500-\mathrm{mL}$ beaker), testing the null hypothesis that the mouthwashes and chemicals used to disinfect complete dentures do not interfere with the superficial microhardness, and can therefore be used as adjuncts to oral hygiene of edentulous patients.

\section{METHODS}

Resins used in this experiment were VipiCril
(Vipi Indústria, Comércio, Exportação de Produtos Odontológicos Ltda., Pirassununga-SP, Brazil) and Bosworth New Truliner ${ }^{\circledR}$ (self-polymerized) (DentalNew Com. Imp. e Exp. Ltda., Curitiba, PR), and 60 specimens of each resin were prepared. These resins were selected because of their domestic commercial use.

The preparation of specimens of resin VipiCril (thermally polymerized) required the preparation of wax pattern $n^{\circ} 7$ (Epoxiglass Ind. e Com. Produtos Químicos LTDA, Diadema-SP) from a plastic mold made of PVC tube, which has a circular shape, diameter of $16 \mathrm{~mm}$ and height of $6 \mathrm{~mm}$. Such mold was isolated in vaseline (LBS Laborasa Ind. Farm. LTDA, São Paulo - SP) and filled with wax $n^{\circ}$ 7. Wax was melted in a spoon by using an alcohol lamp. Upon melting, the wax was placed into the PVC mold. Wax patterns $n^{\circ} 7$ were removed from the plastic mold and inserted into polished brass muffle furnaces $n^{\circ} 6$ (Mac Artigos Odontológicos e Prótese Ind. e Com. LTDA, São Paulo, SP), undergoing the entire process of manufacture of a complete denture base, that is, inclusion, pressing, thermal polymerization (conventional polymerization) and deflasking. Then, exceeding resin is removed by using a tungsten carbide milling bit Maxicut $n^{\circ} 79$ (Vortex, São Paulo - SP) and polishing paper 3M Wetordry of granulation 180.

Specimens of resin Bosworth New Truliner $^{\circledR}$ were prepared by using the same PVC tube mold measuring 16 $\mathrm{mm}$ of diameter and $6 \mathrm{~mm}$ of height. Resin manipulation followed the manufacturer's instructions and used the dosing cups supplied in the package for the use of $6.7 \mathrm{~g}$ of powder per $5 \mathrm{~mL}$ of resin liquid. When material has reached a viscous consistency, the PVC molds were filled with it by using a metallic spatula. The mold was placed between two glass plates (JON Com. de Produtos Odontológicos LTDA, São Paulo, SP) for compression under a $1 \mathrm{Kg}$ weight and kept in such position for approximately 15-20 minutes until its complete polymerization.

After the preparation of specimens they were flattened and polished so that their sides were in parallel and uniform. For such purpose, it was used a metallographic polishing machine: Arotec (Arotec S. A. Ind. e Comércio, Cotia - SP, Brazil). Flattening and polishing of the sides of specimens used a polishing paper 3M Wetordry, starting from a polishing paper of granulation 220 and then using the metallographic polishing machine at high speed for 3 minutes, followed by polishing with polishing papers of granulations 360, 400, 600 and 1200 .

For final polishing, it was used a felt cloth (AROTEC S/A Indústria e Comércio, Cotia, SP) moistened with 
alumina concentrate, suspension $n^{\circ} 3$, of 0.3 micron, pink, with addition of dispersing agent (AROTEC S/A Indústria e Comércio, Cotia, SP) for 3 minutes at high speed, with a load of $215 \mathrm{~g}$, and without refrigeration. Aiming at preventing the interference of the granules from the first polishing papers with the quality of the polishing of the next ones, at every change of granulometry specimens were washed with water for 2 minutes and then dried in paper towel.

Before the initial microhardness tests, specimens were stored in plastic containers duly capped inside an oven for microbiological culture for 48 hours in deionized water at $37^{\circ} \mathrm{C}$, as per the rules of ADA (American Dental Association, 1975) and ISO (International Organization for Standardization Specification 1567, 1988) for the test mentioned above, simulating an environment similar to the mouth.

Then specimens were randomly distributed into four groups for each resin including 15 specimens each and duly numbered from 1 to 15 and identified according to the disinfecting solution, subsequently undergoing a microhardness test before and after cycles of immersion in disinfecting solutions. The following solutions were used for the experiment: $1 \%$ sodium hypochlorite solution (Asfer, Ind. Química Ltda, São Caetano do Sul, SP, Batch: 5023) used to promote disinfection, since it is extremely effective, thus reducing the possibility of causing major changes to the surface of resins, such as change in color stability at higher concentration, $0.12 \%$ chlorhexidine digluconate solution (Musgo Farmácia de Manipulação, Alfenas, MG, Batch: 197660), Corega Tabs ${ }^{\circledR}$ solution (Glaxo Smith Kline, Brazil) and water. These disinfectant solutions were selected because they are more accessible to the population. It is worthwhile to mention that specimens remained in plastic containers duly capped containing $200 \mathrm{~mL}$ of disinfecting solutions such as $1 \%$ sodium hypochlorite solution, $0.12 \%$ chlorhexidine digluconate solution, and Corega Tabs ${ }^{\circledR}$ solution for 10 minutes a day, simulating the time during which the user removes the denture for hygienization, and immersed in water (control) for 8 hours a day, simulating the time during which the user removes the denture to sleep. Thus, the specimens remained immersed in the same disinfectant solution and in the same water (control) for the duration of each cycle, replacing either the solution or water (control) after each microhardness reading, i.e. at the end of each cycle. For disinfectant solutions three cycles were performed (1-30 cycles; 31-90 cycles and 91180 cycles), and it was estimated that 10 minutes daily for the 30-day cycle ( $1^{\text {st }}-30^{\text {th }}$ immersion cycles) accounted for 5 hours; following the same reasoning for the $31^{\text {st }}-90^{\text {th }}$ cycles it was obtained a simulation of 10 hours and for the $91^{\text {st }}-180^{\text {th }}$ cycles, it was obtained a simulation of 15 hours. For deionized water (control) immersion in the three cycles (1-30 cycles, 31-90 cycles and 91-180 cycles) was calculated, for 8 hours daily, so in the first cycle $\left(1^{\text {st }}-30^{\text {th }}\right.$ cycles) it corresponded to a 240-hour simulation; following the same reasoning in the second (31-90 cycles) and third cycles (91-180 cycles) simulation corresponded to 480 hours and 720 hours of immersion, respectively.

For the Knoop hardness test, a microdurometer (HMV-2000/ Shimadzu Corporation, Japan), a highlyspecific device that allows for programming the load weight, the compression time for the specimen and the object lens for the microhardness reading were used. In this experiment, a 25-g load was applied for 10 seconds and the microhardness reading was performed in a 10X object lens. Every specimen underwent four indentations, always at the end of each cycle, and result was expressed as the average of indentations, with an initial reading performed after the $30^{\text {th }}, 90^{\text {th }}$ and $180^{\text {th }}$ cycle of immersion.

Statistical analysis was performed by using a $4 \times 4$ factorial scheme of four solutions (water, $\mathrm{H} 1 \%$, chlorhexidine digluconate and Corega ${ }^{\circledR}$ Tabs) and four evaluation intervals (initial, 1-30, 31-90 and 91-180 cycles of immersion). The average of data obtained was assessed by analysis of variance (Anova) and compared by the Tukey' test at 5\% using software BioEstat 5.0 (Aplicações Estatísticas nas Áreas das Ciências Biomédicas, Belém, Pará, Brazil, 2007).

\section{RESULTS}

Mean values of microhardness of thermally polymerized resin Vipi Cril (Table 1), regardless of the solution studied, were decreased. In the specimens immersed in water (control), the analysis of variance showed a statistical difference related to the microhardness among cycles. The application of the Tukey's test $(p<0.05)$ showed that such statistical difference occurred between cycles 30 and 90 and between the initial and final microhardness. In the $0.12 \%$ chlorhexidine and Corega Tabs $^{\circledR}$ solutions, it was observed a statistically significant difference between the initial reading of microhardness and cycle 30, as well as between the initial and final reading. In the $1 \%$ sodium hypochlorite, no statistical difference was seen between cycles. 
Table 1. Table of descriptive statistical tests for microhardness (KHN) mean values and standard deviation of thermally polymerized resin VipiCril in several solutions at each evaluation interval.

\begin{tabular}{llcccc}
\hline Material & Solution & Initial & $1-30$ cycles & $31-90$ cycles & $91-180$ cycles \\
\hline \multirow{3}{*}{ VIPI CRIL } & Water & $19.0 \pm 3.14$ & $19.4 \pm 2.00$ & $17.6 \pm 1.66$ & $17.5 \pm 1.22$ \\
& $1 \%$ Sodium hypochlorite & $19.6 \pm 1.11$ & $19.5 \pm 0.66$ & $19.2 \pm 1.0$ & $19.1 \pm 1.38$ \\
& $0.12 \%$ Chlorhexidine $^{*}$ & $20.0 \pm 2.36$ & $18.5 \pm 1.30$ & $18.4 \pm 1.59$ & $18.4 \pm 2.40$ \\
& Corega Tabs $^{\circledR}$ & $20.4 \pm 1.60$ & $19.5 \pm 1.17$ & $19.5 \pm 1.00$ & $19.5 \pm 0.85$ \\
\hline
\end{tabular}

The mean values of hardness of self-polymerized resin Bosworth (Table 2) for the solutions tested showed variation of values. In water a statistically significant difference between the initial reading of microhardness and cycle 30 was observed, as well as between cycles 90 and 180 and between the initial and final reading after the conduction of all immersion cycles $(p<0.05)$. In the $1 \%$ sodium hypochlorite significant differences between cycles 30 and $90(p<0.05)$ were observed. Between the initial and final reading there was no statistical difference. In the $0.12 \%$ chlorhexidine solution statistical differences occurred between the initial average reading of microhardness and cycle 30, between cycles 30 and 90 and between the initial and final reading after the conduction of all immersion cycles. In the Corega $\operatorname{Tabs}^{\circledR}$ solution statistic difference was observed between cycles 30 and 90 and between cycles 90 and $180(p<0.05)$.

Table 2. Table of descriptive statistical tests for microhardness (KHN) mean values and standard deviation of self-polymerized resin Bosworth in several solutions at each evaluation interval.

\begin{tabular}{llcccc}
\hline Material & Solution & Initial & $1-30$ cycles & $31-90$ cycles & $91-180$ cycles \\
\hline & Water & $7.23 \pm 0.78$ & $8.99 \pm 0.88$ & $9.10 \pm 0.90$ & $10.06 \pm 1.69$ \\
BOSWORTH & 1\% Sodium hypochlorite & $8.06 \pm 0.94$ & $8.11 \pm 0.81$ & $8.67 \pm 0.51$ & $8.41 \pm 0.83$ \\
& 0.12\% Chlorhexidine & $7.42 \pm 0.64$ & $9.01 \pm 0.78$ & $9.07 \pm 0.60$ & $8.82 \pm 0.68$ \\
& Corega Tabs $^{\circledR}$ & $8.26 \pm 1.11$ & $8.39 \pm 0.75$ & $9.05 \pm 0.86$ & $8.14 \pm 0.96$ \\
\hline
\end{tabular}

\section{DISCUSSION}

In this study, the microhardness values of specimens of thermally polymerized resin VipiCril immersed in water (control) showed an initial increase in the microhardness values (until cycle 30) and then a significant decrease was observed in the next cycle (between cycles 30 and 90). According to our study, Von Fraunhofer and Suchatlampong ${ }^{14}$ also observed in their work a decreased hardness of thermally polymerized resins used for complete denture bases, a phenomenon that is supported by the fact that the immersion in water of complete denture bases made of resin stimulates water diffusion through the resin, saturating it, which results in softening of the surface of such resins, thus decreasing their hardness values. However, Neppelenbroek et al..$^{15}$ observed an increase in hardness of resins Lucitone 550 and QC-20 when immersed for 15 days in water, associating such results to the release of residual monomers and additional polymerization of resins.

The microhardness values of specimens immersed in $1 \%$ sodium hypochlorite were decreased when compared to the initial values, but such result was not statistically significant. However, when comparing this work with the findings of Neppelenbroek et al. ${ }^{15}$ we could notice that acrylic resins Lucitone 550 and QC-20 immersed in $1 \%$ sodium hypochlorite showed a significant decrease of microhardness. According to the author, the sodium from the hypochlorite solution may have penetrated the resins, thus resulting in their softening.

The results for the $0.12 \%$ chlorhexidine solution showed a significant decrease of the hardness mean values between the initial assessment and the $30^{\text {th }}$ cycle, as well as between the initial and final reading, evidencing that the $0.12 \%$ chlorhexidine solution lead to a decrease of the microhardness of such material. Such fact was also seen in the study performed by Neppelenbroek et al. ${ }^{15}$, confirming the hypothesis that the hardness of acrylic resins Lucitone 550 and QC-20 may decrease when immersed in 4\% chlorhexidine digluconate solutions. However, the authors attributed such decrease to the high concentration of $4 \%$ chlorhexidine digluconate. Asad et al. ${ }^{16}$ observed a significant decrease of hardness of thermally polymerized resins Trevalon and D80 FC homopolymer when immersed in $0.5 \%$ chlorhexidine digluconate solution for 7 days and, according to such authors, the change is related to the slow absorption of the disinfecting chemical, leading to a structural alteration of polymer. 
In Corega Tabs ${ }^{\circledR}$ solution decreased microhardness values were seen between the initial assessment and cycle 30 and between the initial and final reading after the application of Tukey's test. A significant decrease of the acrylic resin hardness after immersion in Corega Tabs ${ }^{\circledR}$ solution is evidenced by the findings of Devlin and Kaushik ${ }^{17}$, but the disinfection of acrylic resins performed by them used hot water and alkaline peroxide tablet, which is not indicated by manufacturers, who recommend disinfection with warm water, what did not occur in such experiment. However, the study conducted by Neppelenbroek et al. ${ }^{15}$ confirmed the hypothesis that the hardness of acrylic resins Lucitone 550 and QC-20 may be affected when immersed in $3.78 \%$ sodium perborate solutions (Amosan), attributing such result to the presence of essential and aromatic oils in the Amosan (sodium perborate) formula. Such oils may act on resin surface, dissolving acrylic and thermoplastic resins.

Upon the analysis of results of self-polymerized resin Bosworth, we notice that resins immersed in $1 \%$ sodium hypochlorite, $0.12 \%$ chlorhexidine and Corega Tabs $^{\circledR}$ showed lower microhardness values at the initial assessment, then after immersion cycles a gradual increase of hardness was seen until cycle 90. After the last immersion cycle, a decrease of microhardness values was seen, and such decrease was significant only for the immersion in Corega Tabs ${ }^{\circledR}$ solution. For resins immersed in water a gradual increase of microhardness was noticed, being constant throughout the experiment.

Observing the initial and final reading values after the performance of all immersion cycles, it was noticed that immersions in $1 \%$ sodium hypochlorite and Corega Tabs $^{\circledR}$ solutions did not show a significant statistical difference. However, in water and $0.12 \%$ chlorhexidine digluconate there was a difference related to the increased microhardness, evidencing the results found by Azevedo et al. ${ }^{18}$, who observed increased hardness of resin Duraliner II (self-polymerized reline resin) when immersed in $4 \%$ chlorhexidine digluconate and $1 \%$ sodium hypochlorite solutions for 7 days, relating the phenomena occurred to a higher polymerization and release of residual monomer present in the reaction, what may have overcame the plastifying effect of water absorption. Machado et al. ${ }^{12}$ ruled out the hypothesis that the disinfection of complete denture base with sodium perborate may change hardness properties of denture base and reline materials, since the increased hardness seen for resins Kooliner and Duraliner II may have occurred because of the presence of a certain amount of residual monomer during disinfection procedures. The residual monomer is known as a plastifying agent that reduces the effect of the interchain forces on the polymer, thus leading to an easy deformation during load application in hardness tests. Machado et al. ${ }^{12}$ also report that differences in the composition of the materials assessed may have been partially responsible for such findings. Pinto et al. ${ }^{7}$ observed a decreased hardness of resin Kooliner when immersed in $4 \%$ chlorhexidine digluconate and of resin Jet and Tokuyama Rebase II when immersed in 5.25\% sodium hypochlorite, attributing such result to the plastifying action of disinfecting solutions, thus suggesting a change in the chemical structure of such resins when exposed to repeated disinfection cycles.

Pinto et al. ${ }^{7}$ noticed a decreased hardness of resins Jet, Kooliner and Tokuyama Rebase II when immersed in water, attributing such result to water saturation of resins, resulting in softening of the surface of such selfpolymerized resins, thus decreasing their hardness values. Such result diverges from the findings of this study, which showed increased hardness of resin Bosworth immersed in water.

\section{CONCLUSION}

Within the limitations of the experiment it can be concluded that: a) for resin VipiCril, significant changes ( $p$ $<0.05$ ) were observed on the surface microhardness among the cycles and between the initial and final readings after immersion in solutions of $0.12 \%$ chlorhexidine and Corega Tabs ${ }^{\circledR}$, where it was observed a decrease in microhardness. Resin VipiCril immersed in a solution of $1 \%$ sodium hypochlorite revealed no significant changes in surface microhardness; b) for resin Bosworth, significant changes ( $p<0.05$ ) were observed on the surface microhardness of more than one cycle when immersed in solutions of $0.12 \%$ chlorhexidine and Corega Tabs $^{\circledR}$, revealing an increase in microhardness. In the solution of $1 \%$ sodium hypochlorite, resin Bosworth showed an increase in surface microhardness for one cycle only; c) for resins VipiCril and Bosworth, when immersed in water, significant changes can be observed in microhardness, and for resin VipiCril there was an increase until the $30^{\text {th }}$ cycle and a decrease in the $31^{\text {st }}-90^{\text {th }}$ cycles. For resin Bosworth, when immersed in water, an increased surface microhardness can be observed.

Among the solutions tested, $1 \%$ sodium hypochlorite diluted in $200 \mathrm{~mL}$ of deionized water caused least damages to the surface microhardness of specimens assessed, including resins VipiCril (thermally polymerized resin) and Bosworth (self-polymerized resin). 
Felipe Abreu dos Santos for correcting the translation of the article into English.

\section{REFERENCES}

1. Sartori EA, Schmidt CA, Walber LF, Shinkai RS. Effect of microwave disinfection on denture base adaptation and resin surface roughness. Braz Dent J. 2006;17(3):195-200. doi: 10.1590/S0103-64402006000300004

2. Kulak-Ozkan Y, Kazazoglu E, Arikan A. Oral hygiene habits, denture cleanliness, presence of yeasts and stomatitis in elderly people. J Oral Rehabil. 2002 Mar;29(3):300-4. doi: 10.1046/j.1365-2842.2002.00816.x

3. Evren BA, Uludamar A, Iseri U, Ozkan YK. The association between socioeconomic status, oral hygiene practice, denture stomatitis and oral status in elderly people living different residential homes. Arch Gerontol Geriatr. 2011 NovDec;53(3):252-7. doi: 10.1016/j.archger.2010.12.016

4. Paranhos HFO, Silva-Lovato $\mathrm{CH}$, Souza RF, Cruz PC, Freitas $\mathrm{KM}$, Peracini A. Effects of mechanical and chemical methods on denture biofilm accumulation. J Oral Rehabil. 2007 Aug;34(8):606-12. doi: 10.1111/j.1365-2842.2007.01753.x

5. Budtz - Jorgensen E. Materials and methods for cleaning dentures. J Prosthet Dent. $1979 \mathrm{Dec} ; 42(6): 619-23$.

6. Barnabé W, De Mendonça Neto T, Pimenta FC, Pegorarro LF, Scolaro JM. Efficacy of sodium hypochlorite and coconut soap used as disinfecting agents in the reduction of denture stomatitis, Streptococcus mutans and Candida albicans. J Oral Rehabil. 2004 May;31(5):453-9. doi: 10.1111/j.13652842.2004.01254.x

7. Pinto TMS, Neves ACC, Leão MVP, Jorge AOC. Vinegar as an antimicrobial agent for control of Candida spp In complete denture wearers. J Appl Oral Sci. 2008 Nov-Dec;16(6):385-90. doi: 10.1590/S1678-77572008000600006

8. Andrade IM, Cruz PC, Silva-Lovato CH, Souza RF, SouzaGugelmin MCM, Paranhos HFO. Effect of chlorhexidine on denture biofilm accumulation. J Prosthodont. 2012 Jan;21(1):26. doi: 10.1111/j.1532-849X.2011.00774.x.

9. Sartori EA, Schmidt CB, Mota EG, Hirakata LM, Shinkai RS. Cumulative effect of disinfection procedures on microhardness and tridimensional stability of a poly(methyl methacrylate) denture base resin. J Biomed Mater Res B Appl Biomater. 2008 Aug;86(2):360-4. doi: 10.1002/jbm.b.31027

\section{Collaborators}

EG MARTINS and RT MORETTI NETO participated in all stages of preparation of the article.

10. Pavan S, Arioli-Filho JN, Santos PH, Nogueira SS, Batista US Effect of disinfection treatments on the hardness of soft denture liner materials. J Prosthodont. 2007 Mar-Apr;16(2):101-6. doi: 10.1111/j.1532-849X.2007.00162.x

11. Consani RLX, Mesquita MF, Mendes WB, Arioli-Filho JN. Effect of microwave disinfection on physical and mechanical properties of acrylic resins. Braz Dent J. 2008;19(4):348-53. doi: 10.1590/ S0103-64402008000400011

12. Machado AL, Breeding LC, Vergani CE, Perez LECP. Hardness and surface roughness of reline and denture base acrylic resins after repeated disinfection procedures. J Prosthet Dent 2009; 102:115-122. doi: 10.1016/S0022-3913(09)60120-7.

13. Pavarina AC, Pizzolitto AC, Machado AL, Vergani CE, Giampaolo ET. An infection control protocol: effectiveness of immersion solutions to reduce the microbial growth on dental prostheses. J Oral Rehabil. 2003 May;30(5):532-6. doi: 10.1046/j.13652842.2003.01093.x

14. Von Fraunhofer JA, Suchatlampong $C$. The surface characteristics of denture base polymers. J Dent 1975; 3: 105-109

15. Neppelenbroek KH, Pavarina AC, Vergani CE, Giampaolo ET. Hardness of heat-polymerized acrylic resins after disinfection and long-term water immersion. J Prosthet Dent. 2005 Feb;93(2):171-6. doi: 10.1016/j.prosdent.2004.10.020

16. Asad T, Watkinson AC, Huggett R. The effects of various disinfectant solutions on the surface hardness of an acrylic resin denture base material. Int J Prosthodont. 1993 JanFeb;6(1):9-12.

17. Devlin $\mathrm{H}$, Kaushik $\mathrm{P}$. The effect of water absorption on acrylic surface properties. J Prosthodont. 2005 Dec;14(4):233-8. doi: 10.1111/j.1532-849X.2005.00050.x

18. Azevedo A, Machado AL, Vergani CE, Giampaolo ET, Pavarina AC, Magnani R. Effect of disinfectants on the hardness and roughness of reline acrylic resins. J Prosthodont. 2006 JulAug;15(4):235-42. doi: 10.1111/j.1532-849X.2006.00112.x 


\section{Erratum}

In the article published in RGO, Rev. Gaúch. Odontol. vol.65 no.3, p. 196-201, jul./sep. 2017; "Dental trauma in contact sports", should to publish the following erratum:

Substitute, the published article twice "Dental trauma in contact sports", LOPES, Luísa Bandeira Pires Monteiro; FERREIRA, Joana Freire.

For the article: "Effect of repeated cycles of chemical disinfection in microhardness of acrylic resins of complete denture base", MARTINS , Elisa das Graças; MORETTI NETO, Rafael Tobias. 